\title{
Pozitif Davranış Desteğinin Eğitim Sürecindeki Yeri, Önemi ve Uygulaması*
}

\section{Fuat TANHAN*** Özlem ÇEVİK***}

Öz: Okullarda artan disiplin sorunları, şiddet, uyuşturucu ve benzeri maddelerin kullanımı; okul iklimini ve okul güvenliğini ciddi anlamda tehdit etmektedir. Bu sorunları aşmak için artırılan disiplin cezaları istenilen sonucu verememektedir. Bu sorunları çözmede disiplin cezalarını arttırmak yerine Amerika'da ve Avrupa'da pek çok okulda Pozitif Davranış Desteği (PDD) yaygın bir şekilde kullanılmaktadır. Çalışmalar PDD’nin uygulandığı okullarda, disiplin sorunlarının ve diğer sorunların azaldığını göstermektedir. PDD, okullarda önleyici ve geliştirici bir rol oynar ve PDD, geleneksel okul uygulamalarına alternatif bir yol olarak kabul edilir. Yabancı literatürde PDD’yle ilgili pek çok çalışmaya rastlamak mümkündür. Fakat Türkiye'de PDD’yle ilgili sınırlı sayıda çalışma bulunmaktadır. Bu çalışmanın amacı, eğitim süreçlerine değerli katkıları olan PDD’yi okuyuculara tanıtmaktır. Bu çalışma literatür çalışması olup çalışmada betimsel metot kullanılmıştır. Bu araştırma için PDD’yle ilgili yapılan çalışmalar incelenmiştir ve bu çalışmalar, araştırmanın kaynaklarını oluşturmaktadır. Eğitim süreçlerindeki yeri, önemi ve uygulamalarıyla tanıtılan PDD ulaşılabilen literatür kaynaklar bağlamında betimlenmeye çalışılmıştır.

Anahtar Kelimeler: Pozitif davranış desteği, güvenli okul, eğitim süreci

\footnotetext{
* Bu çalışma Van Yüzüncü Yıl Üniversite'de yapılan doktora tez çalışmasından türetilmiştir.

** Van Yüzüncü Y1l Üniversitesi Eğitim Fakültesi, Eğitim Bilimleri Bölümü, Türkiye. ORCID ID:0000-000219904988, E-posta: ftanhan@yyu.edu.tr

*** Van Yüzüncü Yıl Üniversitesi Eğitim Fakültesi, Eğitim Bilimleri Bölümü, Türkiye. ORCID ID:0000-0002-

4637-2147, E-posta: ozlem.alav@gmail.com
}

\begin{tabular}{lll}
\hline Gönderim:29.05.2018 & Kabul:08.07.2018 & Yayın:29.10.2018 \\
\hline
\end{tabular}


The Place, the Importance and the Application of Positive Behavior Support in the Education Process

Abstract: Increasing disciplinary problems, violence, the use of drugs in schools are serious threats to school climate and school security. Increasing disciplinary punishments cannot overcome these problems. Instead of increasing disciplinary punishment to solve these problems, Positive Behavior Support is widely used in many schools in America and Europe. Studies show that schools with positive behavior support reduce disciplinary and other problems. Positive behavioral support plays a preventive andpromoting role in schools and positive behavioral support is considered an alternative to traditional school practices. It is possible to find many studies about positive behavior support in literature. However, there are limited studies on positive behavior support in Turkey. The aim of this study is to introduce readers to Positive Behavior Support, which is a valuable contribution to the educational process. This study is a literature study and adescriptive method is used for the study. Previous studies about positive behavior support have been analyzed and these studies are the sources of thestudy. The Positive Behavior Support which is introduced with its place, importance and applications in the education process has been tried to be described in the context of available literature sources.

Key words: Positive behavior support, safe school, education process

\section{Giriş}

Okullarda, okul iklimine ve öğrencilerin akademik ve sosyal becerilerine olumsuz yönde etki eden disiplin sorunları vardır. Her okul, kendi içerisinde bir şekilde bu sorunları çözmeye çalışır ve çözüm yolu da genellikle disiplin cezalarını artırma şeklinde olur; çünkü disiplinle, problemli davranışların azalacağı ve sosyal becerilerin gelişeceği farz edilir ve 
disiplini sağlamak için cezalandırma yöntemi gibi yöntemler kullanılır ve bu yolun, etkili bir yol olduğu kabul edilir (Glover, 2005, s. 60). Fakat bu çabalara rağmen okuldaki disiplin sorunları varlığını sürdürmeye devam eder. Disiplin cezalarının katılaşmasına ve artmasına rağmen okuldaki sorunların çözülmeyişi bu yöntemin çok fazla etkili olmadığına işaret eder. Disiplin cezalarının arttırılması yerine okulda önleyici ve geliştirici planlamaları geliştiren ve geleneksel disiplin uygulamalarının alternatifi olan PDD (Safran ve Oswald, 2003), okul ikliminin güvenli hale getirilmesi için okul genelinde bir sistem oluşturur (Horner, Sugai, Smolkowski, Eber, Nakasato, Todd ve Esperanza, 2009;Simonsen, Sugai ve Negron, 2008; Sugai ve Horner, 2002) vePDD'nin uygulandığı okullarda, disiplin problemlerinin düştüğü görülür (Bohanon ve $\mathrm{Wu}, 2014)$.

25 yılın üzerinde bir geçmişe sahip olan PDD terim olarak iki açıdan incelenebilir. Birincisi, pozitif davranışı, destekleme; diğeri ise problemli davranışı pozitif davranış olarak değiştirmektir. Birincisinde yani pozitif davranışı desteklemekten kastedilmek istenilen; uyarlanır olumlu sosyal davranışları içeren pozitif davranışları desteklemektir. Bu yüzden PDD, pozitif davranışlara cesaretlendirmeyi, onları arttırmayı ve güçlendirmeyi çabalama anlamına gelir; başka bir deyişle pozitif davranışı destekleme anlamına gelir. İkincisi ise, yani davranış desteği, problemli davranışı pozitif olarak değiştirme anlamına gelir (Dunlap, Kincaid, Horner, Knoster ve Bradshaw, 2014; Kincaid, Dunlap, Kern, Lane, Bambara, Brown, Fox ve Knoster, 2016; Ziomek-Daigle ve Cavin, 2015).

İlk zamanlar, duygusal ve davranışsal engelleri olan öğrencilere, sağlıklı öğrencilerle eşit eğitim ortamlarını sağlamak için ortaya çıkan PDD, 2004 yılından itibaren okuldaki bütün öğrencilere yönelik bir sistem haline gelmiştir(Children's Defense Fund; Garcia, 2014). Amerika ve Avrupa' da yaygın bir şekilde kullanılan PDD, ilk zamanlarda ilkokul ve ortaokulda kullanılırken başarılı olmasının ardından okulöncesi ve liselerde de yaygınlaştırma çalışmaları 
başlatılmış ve pozitif davranış desteği, beklenen başarısını okul öncesi(Stormont, Lewis ve Beckner, 2005) ve lisede de yakalamıştır.Yabancı literatürde sıkça rastlanan ve yaygın olan PDD’yle ilgili Türkçe sınırlı yayına rastlanmaktadır. PDD, Türkiye eğitim sistemine de fayda sağlayabileceği düşünülebilir. Bu nedenle PDD’ye yönelik yapılacak her türlü yayın Türkiye’de PDD’nin tanıtılması ve uygulanması açısında önemlidir. Bu çalışmanın amacı, Amerika ve Avrupa eğitim sisteminde başarıyla uygulanan PDD’nin eğitim sürecindeki yerini, önemini ve uygulamalarını ulaşılabilen literatür bağlamında okuyuculara tanıtmaktadır.

\section{Yöntem}

$\mathrm{Bu}$ araştırma alanyazın taraması ile yürütülen betimsel bir araştırmadır. Tarama modelleri, geçmişte ya da halen var olan bir durumu var olan şekliyle betimlemeyi amaçlayan araştırma yaklaşımlarıdırlar. Araştırılan olay, birey veya nesne kendi koşulları içerisinde tanımlanmaya çalışılır. Onlara herhangi bir müdahale yapılmaz, etkileme çabasına gidilmez (Karasar, 2011, s.77). Bu çalışma bir literatür çalışmasıdır. Literatür taramaları, araştırma problemiyle ilgili bilgilerin ve literatürün özeti, sentezi ve incelemesidir (Balc1, 2013). PDD ile ilgili literatürde çok çeşitli bilgi ve kaynak bulunmaktadır. Fakat bu kaynakların neredeyse tamamına yakının İngilizce'dir. PDD’nin genel olarak eğitimdeki yeri, önemi ve uygulamalarının nasıl olduğunu kademelere göre açıklayan kaynağa rastlanmamıştır ve her bir konuyla ilgili bilgi dağınık durumdadır. Türkçe okuyan okuyucu ve eğitimcilere PDD’yi eğitim sürecindeki yeri, önemi ve uygulamalarıyla genel olarak tanıtmak önem arz etmektedir. Ayrıca PDD Türkiye'de oldukça yeni bir kavram olduğu için PDD’yi genel yapısıyla açıklamak gerekmektedir.

$\mathrm{Bu}$ çalışmada, PDD ile ilgili bilgilere ulaşmak için devlet tabanlı siteler (http://www.apbs.org/new_apbs/genintro.aspx, https://www.pbis.org/ ) ve ERIC, scopus, SSCIgibi veri tabanları esas alınmıştır. ERIC, eğitimle ilgili araştırma ve literatür bilginin tam 
metin olarak araştırmacılara sunan bir veri tabanıdır. ERIC, ABD Eğitim Bakanlı̆̆ı Eğitim Bilimleri Enstitüsü tarafından desteklenmektedir.SSCI, sosyal bilimler alanındaki dergilerin tarandığı veri tabanıdır. Scopus, en geniş hakem denetimli literatür (bilimsel dergiler, kitaplar ve konferans raporları) özet ve atıf veri tabanıdır. Bu veri tabanlarının yanı sıraresmi internet siteleri ve konuya ilişkin araştırmacıların yaptıkları çalışmalar da kaynak olarak kullanılmıştır.

Konuyla ilgili araştırma yapılırken positive behavior support, positive behavioral support, positive behavioral interventions supports, positive behavioral interventions and supports, positive behaviors, positive behavior management strategies, positive behavior management plan ve positive behavior management anahtar kelimeleri bulunmuştur. Konuyla ilgili Türkçe literatürde üç yayına, yabancı literatürde ise yüze yakın yayına rastlanılmıştır. Fakat pozitif davranış desteğiyle ilgili 600'ün üzerinde çalışmanın mevcut olduğu belirtilmektedir (Crimmins, Farell, Smith, Bailey, 2007).Bu çalışmalar arasında pozitif davranış desteğinin okul öncesi, ilkokul, ortaokul ve lise uygulamaları vardır. Ayrıca pozitif davranış desteğinin genel yapısı ve sistemini anlatan çalışmalarda mevcuttur. Pozitif davranış desteğiyle ilgili okulların kendi çalışmaları da mevcut olmasına rağmen bu çalışmada onlara yer verilmemiştir. Çünkü okulların yürüttüğü pozitif davranış desteği çalışmaları kendi okullarıyla ilgili bilgi vermekte olup pozitif davranış desteğinin eğitimdeki yeriyle ilgili bilgi vermemekteydi. Ayrıca bu çalışmalardan bazıları kendi geliştirdikleri form üzerinden bilgi sunmaktaydılar. Türkiye'deki okullarda pozitif davranış desteği sistemi olmadığı için bu formlarla ilgili verilecek bilgiler herhangi bir çalışmada karşılık bulamayacaktı ve bu çalışmalar, bu çalışmanın kapsamı içerisinde yer almadığından çalışmaya dâhil edilmemiştir. Bunun yanı sıra pozitif davranış desteğiyle ilgili özellikle son 5 yılın çalışmaları bu araştırmanın kapsamına alınmıştır. 


\section{Bulgular}

\section{Pozitif Davranış Desteği}

Pozitif Davranış Desteği diğer adıyla Pozitif Davranış Yönetimi, uygulamalı bir bilim olarak Avrupa ve Amerika'daki okullarda yaygın olarak kullanılan bir sistem ve programdır (Carr, Dunlap, Horner, Koegel, Turnbull, Anderson, Sailor, Anderson, Albin, Koegel ve Fox 2002; Johnston,Foxx, Jacobson, Green ve Mulick 2006; Sugai ve Flannery, 2005). Rogers, kitabında PDD'den isim olarak bahsetmese de ana uygulamaları, felsefesi, uygulama şekli ve ilkeleriyle okul genelinde uygulanması gereken bir sistem olarak pozitif davranış desteğinden bahseder. Bu fikrin, ilk ortaya atıldığı dönemlerde, bazı insanlar tarafından bu uygulamanın mümkün olamayacağına dair eleştirilerin olduğunu ve zamanla bu uygulamanın başarılı olmasıyla ön yargıların kırılmaya başladığını anlatır (Rogers, 1994, s.151-158). Fakat alan yazınında PDD ilk defa 1990 yılında Horner ve arkadaşları tarafından kullanılmıştır (Dunlap, vd. 2014) ve ilk olarak 1997 yılında davranışsal ve duygusal engeli olan öğrenciler içinuygulanan PDD 2004 yılından itibaren, okullarda, bütün öğrencilere yönelik olarak uygulanmıştır (Horner, Todd, Lewis-Palmer, Irvin, Sugai ve Boland, 2004).

“Pozitif Davranış Desteği” (PDD) terimi, 1980’lerin ortalarında ortaya çıkmıştır. Yüzlerce makale, kitap, el kitabı ve web sitesi, PDD'nin açıklanması, yayılması ve araştırılması için insanların hizmetine sunulmuştur.Kısa bir tarihçesi olan PDD, "PozitifDavranış Desteği", "Pozitif Davranışsal Destek", "Pozitif Davranışsal Destekler" ve "Pozitif Davranışsal Müdahaleler ve Destekler" gibi çeşitli terimlerle biliniyor. Farklı terimlerin yaygınlaştırılması ve kullanılması karışıklığa neden olabilmektedir. Terminolojideki bu çeşitlemelerden bazıları hafif görünebilir - örneğin "davranış" yerine "davranışsal" kullanılması - ne olursa olsun, terminolojideki küçük farklılıklar bile iletişimde engel oluşturabilir ve alanda yorumlama ve 
uygulama üzerinde olumsuz etkiler bırakabilir. Bu kavramlar, kısaca aşağıdaki gibidir (Dunlap, vd. 2014; Horner, Sugai, Smolkowski, Eber, Nakasato, Todd ve Esperanza, 2009):

Pozitif Davranış Desteği, hem pozitif davranışları desteklemek hem de problemli davranışları pozitif davranışlar olarak değiştirmek anlamına gelmektedir(Dunlap, vd. 2014; Horner, vd., 2009; Bohanon ve Wu, 2014).

Pozitif Davranışsal Destek, terimi, pozitif davranış desteği terimine çok benzese de artık daha az tercih edilmektedir, çünkü "davranışsal", destek için bir değiştirici ayırt edici bir özellik olmaktadır. Bu terim pozitif davranış desteğinin geleneksel yöntemlerden doğduğu anlamına benzer bir anlam taşır(Dunlap, vd. 2014; Horner, Todd, Palmer, Irvin, Sugai ve Boland, 2004; Horner, vd., 2009).

Pozitif Davranış(sal) Destekler, PDD etiketlemesine yönelik bu yaklaşımda, pozitif davranış desteğinden ayrımı birden çok "destek" anlamına gelmesidir. Diğer alternatiflerle olduğu gibi, PDD'nin birçok müdahale seçeneği ve PDD planları "çok bileşenli" olarak bilinen bu kullanım için bir miktar meşrutiyet vardır. Bununla birlikte, vurgu, müdahale stratejilerinin çoğulculuğu üzerinedir. Bu vurgu yanlıştır. Bunun yerine, vurgu, işlevsel ve bağlamsal değerlendirme sürecine ve sonuçta, bireysel ve / veya sistematik analiz birimlerine yönelik destek ve müdahale etkili planlarının oluşturulması ve uygulanması sürecine dâhil olması gerekir (Dunlap vd., 2014; Stormont, Lewis ve Beckner, 2005).

Pozitif Davranışsal Müdahaleler ve Destekler, PDMD, okul ortamında PDD yaklaşımlarının uygulanmasına ve özellikle okul çapındaki uygulamalara değinmiştir. Fakat PDMD, daha çok engelli bireyleri desteklemek anlamında kullanılırken PDD, bütün öğrencileri desteklemek anlamındadır (Dunlap vd., 2014). 
İlk dönemlerde, pozitif davranış desteği terimi, davranış yönetiminin uygulamalarını ifade etmek için kullanılırdı. Pozitif davranış desteğinin ilk uygulamaları, "caydırıcı olmama" ile etiketlendirilmişti ve birçok yazar, genel davranış yönetimi stratejilerindeki sınırlılıkları tanımlamaya ve alternatifleri belirlemeye başladılar (Dunlap, vd., 2014). Başka bir deyişle, pozitif davranış desteğinin ilk uygulamaları başarıyı yakalayamamıştı ve araştırmacılar, bu başarısızlıkların nedenlerini belirleyip alternatifleri tanımlamaya başladıktan sonra pozitif davranış desteği bugünkü başarısını yakalamıştır. Pozitif davranış desteği uygulamalarının, başarıya ulaşması için de zaten ihtiyaçların sürekli olarak değerlendirilmesi ve çalışanlara ve öğrencilere profesyonel destek sağlanması gerekir (Bohanon ve Wu, 2014; Simonsen, Sugai ve Negron, 2008).

Pozitif Davranış Desteği, uygulamalı bir bilimdir ve davranış değiştirme programıdır.PDD, gelişim evlerine göre (okul öncesi, ilkokul, ortaokul, lise) ve öğrenci özelliklerine göre (devlet okulu, özel okul, alternatif okul) ve amacına göre (özel eğitim, zihin sağlığı, çocuk adaleti) değişebilmektedir. Ayrıca pozitif davranış desteği, her okul için farklı olabilmektedir. Çünkü her okulda yaşanan sorunlar ve buna bağlı olarak ortaya çıkan ihtiyaçlar farklı olabilir. Örneğin, bir okulda şiddete yönelik davranışlar fazlayken başka bir okulda akademik gerilik şeklinde sorunlar fazla olabilir. Pozitif davranış desteği mantığına göre, bu durumda her okulun verilerine göre sorunları belirlenmeli ve buna yönelik programlar geliştirilmelidir (Garcia, 2014;Mcintosh, Mercer, Hume, Frank, Turri ve Mathews, 2013; Simonsen, Jeffrey-Pearsall, Sugai ve McCurdy, 2011).

Pozitif davranış desteği, üç ana tema üzerine kuruludur:

(a)-önleme,

(b)-çok yönlü destek 
(c)-veriye dayalı karar verme.

Pozitif davranış desteğinin temelini oluşturan bu üç tema, okuldaki genel sistemin ana iskeletini oluşturur ve pozitif davranış desteğine dayalı hazırlanan programlar, bu üç temaya göre şekillenir ve bu programlar genel olarak psiko-eğitim programlarıdır (Sprague ve Horner, 2007; Horner, Sugai ve Anderson, 2010).

PDD, genel olarak okulun hepsinin içine alan bir sistemdir (Simonsen, Jeffrey-Pearsall ve Sugai, 2011) ve PDD, okuldaki öğrencileri üç kategoride inceler. Bunlardan birincisi okulda problemli davranış göstermeyen genel olarak okul kurallarına uyan ve kendilerinden beklenen sorumlulukları yerine getiren öğrencilerdir ve bu öğrenciler, okulun yaklaşık olarak \%80'nini oluşturur. İkincisi, okulda problemli davranış gösterme riski taşıyan öğrencilerdir ve bu öğrenciler okulun yaklaşık olarak \%15'ini oluşturur. Bu grupta yer alan öğrenciler, okuldaki davranış problemleri gösterme riski olan öğrencilerdir. İlk gruptaki öğrencilerle bu gruptaki öğrenciler kıyaslandığında ilk gruptaki öğrenciler için gerekli önlemler alınmazsa bu gruba girecek ilk grup öğrencileri olabilir. Ayrıca ikinci grupta yer alan öğrenciler içinde gerekli önlemler alınmalıdır. Buradaki ana hedef, onları tanımaya çalışmak ve gerekli desteğin verilmesidir. Üçüncü grupta ise kronik olarak problemli davranış sergileyen öğrenciler vardır. Bu öğrencilere genelde bireysel müdahale ve takip gerekir (Pişkin, Öğülmüş ve Boysan, 2011, s. 13-14). 


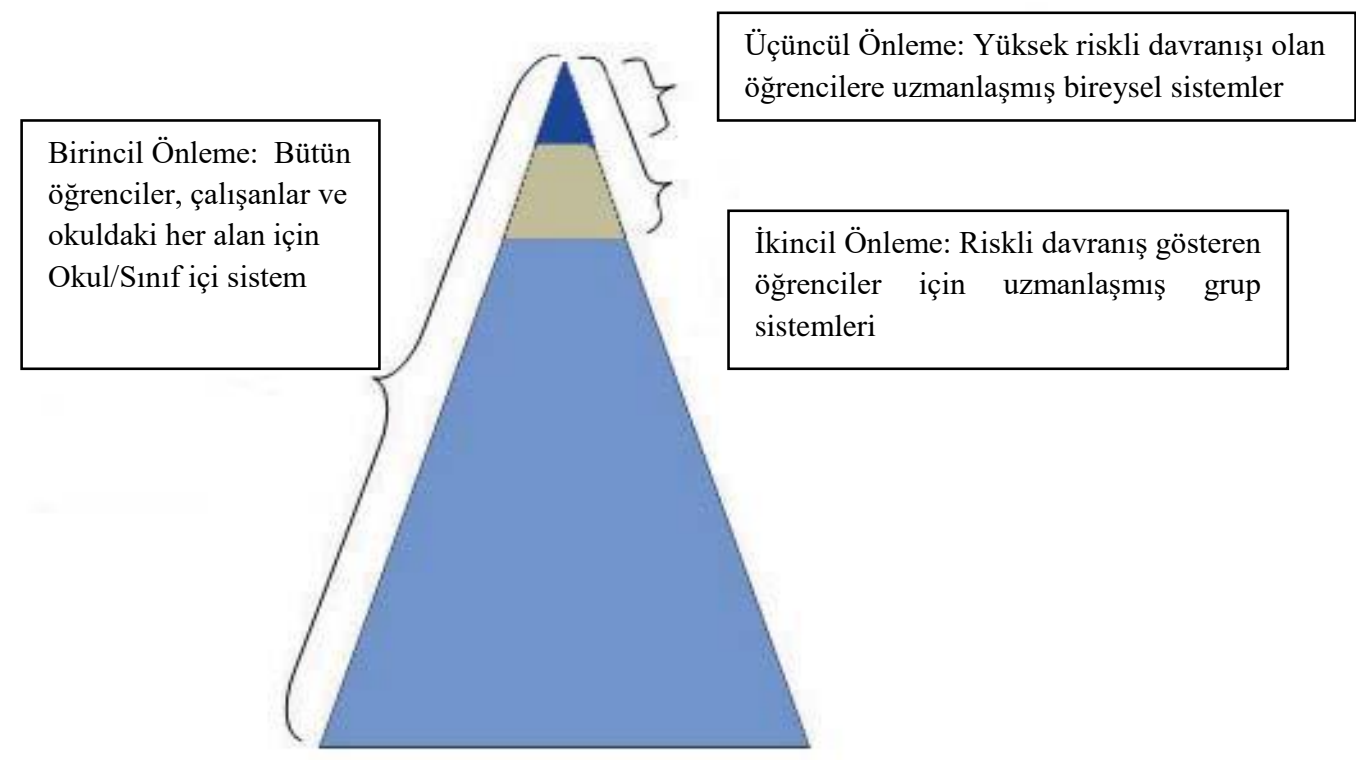

Şekil 1:Pozitif Davranış Desteğinin Okul Genelindeki Çalışma Sistemi (Simonsen, Sugai ve Negro, 2008)

Şekil 1'den anlayacağımız üzere, PDD'nin okul genelinde çalışma sistemi üç şekilde olmaktadır. Birincil önleme olarak PDD, okuldaki bütün öğrencilere yöneliktir. Birincil önlemede yer alan çalışmalar, okulun kantin, koridor, sınıf vb. bütün alanlarında öğretmen, kantinci, temizlik personeli gibi okuldaki tüm çalışanları işe dâhil ederek bütün öğrencilere yönelik genel pozitif davranışları kazandırmaya çalışır. İkincil önleme olarak, PDD okulda saldırganlık davranışları gibi belli davranış problemleri gösteren öğrencileri kategorilere ayırır ve bu öğrencilere yönelik uzman kişi eşliğinde özelleştirilmiş ya da uzmanlaştırılmış müdahale programları uygulanır. Üçüncül önlemede, yüksek riskli davranış sergileyen öğrenciye uzman kişi, bireysel müdahalede bulunur (Simonsen, Sugai ve Negro, 2008; Pişkin, Ögüülmüş ve Boysan, 2011).

\section{Pozitif Davranış Desteği ve Eğitim}

Birey, yıkıcı bir çocukluk geçirmişse ve olumsuz dış dünyayla erken yaşlarda tanışmışsa başkalarına veya kendisine zarar vermek amacıyla şiddet içeren dış dünyaya karşı, tepki olarak 
saldırganca davranışlar geliştirebilir (Köklü, 2006). Bu sebeple öğrencilerin özellikle de okulöncesinde ve ilkokulda olabildiğince sağlıklı okul ortamına ihtiyacı vardır. Okulun, öğrenci için güvenli bir çevre olması en az aile ortamı kadar önemlidir. Öğrencilerin zihinsel ve ruhsal sağlığının korunması için okulun örgütsel stratejilerinin olması gerekir. $\mathrm{Bu}$ nedenle öğrencilerin, zihin ve ruh sağlığını bozacak ortamlar yerine güvenli bir okul ortamına ihtiyaçları vardır. Bunun sağlaması için önce sınıfta daha sonra da okul genelinde güvenli ortamların oluşturulması lazım. (Knoff, 2000). Öğrencilerin sosyal-duygusal durumları ve akademik öğrenmeleri arasında sıkı bir ilişki vardır. PDD uygulamaları, öğrencilerin akademik ve sosyal becerilerini geliştirmektedir. PDD, çocuğa yönelik olup aynı zamanda bireysel temellidir. PDD, uygulamalarının başarılı olması için danışman ve ailenin işbirliğiyle çalışması lazım (Waller, Gardner, Dishion, Sitnick, Shaw, Winter ve Wilson,2015). Böylelikle aile hem çocuğundan haberdar olacak hem de çocuğuyla ilgili sorunlarda uzman desteğini alıyor olacak. Okul açısından bakıldığında, okul öğrenciyle ilgili problemlere aileyi dâhil ederek görev paylaşımı yapılmış olacak ve aileyi bilgilendirerek hem davranış değişikliğini kolay sağlıyor hem de sorumluluk paylaşarak üzerindeki yükü azaltıyor olacak(Gottfredson, Gottfredson ve Hybl, 1993).

Okulda yalan söyleyen veya kopya çeken bir öğrenci, evde veya toplumda da yalan söyler ve başka bir suç işleyebilir. Okulda hırsızlık yapan veya kavga eden öğrenciler, genelde polisin müdahil olduğu suç ilerine karışabilmektedirler. Aynı öğrenciler sıklıkla ilaç kullanımına da dâhil olmaktadırlar. (Gottfredson, Gottfredson ve Hybl, 1993). Buradan anlaşıldığı okulda problemli davranışlar sergileyen öğrencilerin okul dışındaki hayatlarında da benzer davranışları sergileyeceği düşünülür. Bu nedenle okulun toplumu düzenlemek için de kendi yapısı içerisinde başta şiddet olmak üzere var olan sorunları bir sistem içerisinde çözmesi gerekir. Fakat bazı okullar ve öğretmenler de öğrencileri yeteri düzeyde ve doğru şekilde yönlendirmemektedir. Bu nedenle okullarda uzman bir takımın olması ve gerekli noktalarda 
öğretmenlere ve okul yönetimine destek vermesi gerekir. Pozitif davranış desteği, okullara ve öğretmenlere ihtiyaç duydukları desteği sağlayarak öğrenciyi olabildiğince topluma kazandırmayı ve akademik başarılarını arttırmayı hedefler (Dunlap, vd., 2014).

Okuldaki problemli davranışları, üç grupta sınıflamak mümkündür; (1)Bazı bireyler diğerlerine göre daha fazla problemli davranış gösterebilir, (2) Bazı öğretmenler, sınıfta daha fazla yanlış yönlendirme eğilimindedirler ve (3) Bazı okullar, öğrencilerin davranışlarını kontrol etmede başarısızdırlar (Gottfredson, Gottfredson ve Hybl, 1993). Okulda pozitif davranış desteği sisteminin başarılı olması okul takımı, okul yönetimi, öğretmenler gibi birçok faktörden etkilendiği için etkililik hem uygulamanın niteliğine hem de uygulayıcının becerisine bağlıdır (Mcintosh, vd., 2013).

PDD, bireye bir takım pozitif davranışları öğreterek şiddet davranışı, ders çalışmama, okul kurallarına uymama, çevresine saygılı olmama, sorumluluk davranışı göstermeme, anti sosyal davranışlar gibi davranışları önlemeyi veya azaltmayı hedefler. Çalışmalar, pozitif davranış desteğinin kullanıldığı okullarda,alkol ve uyuşturucu kullanımı, okulu bırakma veyaokuldan kaçma ve diğer davranış sorunlarının azaldığını göstermektedir (Wilson, Gottfredson ve Najaka, 2001). PDD’nin kullanıldığı okullarda, uygun davranışların arttı̆̆ı, uygun olmayan davranışların azaldığı, davranış desteğine cevap veren öğrencilerin oranında artış olduğu, bireysel eğitim hedeflerinin karşılandığı görülmektedir (Simonsen vd., 2011; Simonsen, Britton ve Young, 2010).

\section{Pozitif Davranış Desteğinin Uygulamaları}

Pozitif Davranış Desteği programları, ülke genelinde uygulanan programlar olmasına rağmen, her bölgenin her okulun kendine özgü PDD programı olabilmektedir; çünkü PDD programı, okulun, bölgenin ihtiyaç ve beklentilerine göre hazırlanır ve sürekli olarak değerlendirilip revize edilir (Mcintosh, vd., 2013).PDD, okul genelinde uygulanan bir sistem 
olmasına rağmen okul içinde hedef popülâsyonu bile değişebilmektedir. Örneğin, pozitif davranış desteğinin bazı uygulamaları okuldaki bütün öğrenci popülâsyonu içinken bazı uygulamaları otistik ya da ödev yapmayan öğrenci popülâsyonuna yönelik olabilmektedir (Horner, Sugai ve Anderson, 2010). Öğrencilerin sosyal-duygusal durumları ve akademik öğrenmeleri arasında sıkı bir ilişki vardır. PDD uygulamaları, öğrencilerin akademik ve sosyal becerilerini geliştirmektedir.PDD, çocuğa yönelik olup aynı zamanda bireysel temellidir. PDD uygulamaları başarılı olmak için danışman ve ailenin işbirliğiyle çalışır (Waller, vd., 2015).

PDD’nin uygulamaları, sınıf ortamına ve okul geneline bağlıdır (Feuerborn, Tyre ve King, 2015) ve eğitimin her seviyesinde uygulanan PDD birbirinden farklıdır; çünkü bireylerin gelişimi ve ihtiyaçları okul seviyelerine göre birbirinden farklılaşmaktadır. Buna bağlı olarak geliştirilen programlar ve yöntemler de farklılık gösterebilmektedir. Örneğin okul öncesi için tanımlanan bir uygulama lise için uygun olmayacaktır (Horner, Sugai ve Anderson, 2010). Aşağıda genel olarak okul seviyelerinde uygulanan pozitif davranış desteği açıklanmıştır.

Okulöncesi dönemde pozitif davranış desteği. Okulöncesi dönemde uygulanan PDD, okul geneli yerine program geneli pozitif davranış desteği terimini kullanır. Program geneli pozitif davranışı, okul genelinde pozitif davranış uzmalarından oluşan takım destekler. $\mathrm{Bu}$ takımda öğretmenler, uzman yardımcılar, öğretim yardımcıları, konuşma ve dil pedagogu, okul psikologları, part time çalışan davranış danışmanları ve programda yer alan çocukların velileri bulunur. Okul öncesinin takımları, ilkokul ve okuldaki pozitif davranış desteği takımından çok daha geniştir; çünkü okul öncesinin takımı birebir sorunlarla ilgilenir. Bu takım, iletişimi ve işbirliğini sağlar. En az ayda bir kez olmak üzere ne kadar sık toplanması gerekiyorsa toplanılır. Başarının sağlanması için, bütün okul öncesi öğretmenleri, takımın aldığı kararları uygular. Takım her yıl, gerçekleştirilmesi gereken amaçları öğrencilerin bireysel durumu ve ihtiyaçlarına göre belirler. Takım beklenen davranışların hangileri olduğunu, ne zaman ve nasıl 
öğretileceğineve bu davranışların öğretilip öğretilmediğine dair verilerin nasıl değerlendirileceğine karar verir. Pozitif davranış desteği takımının ilk işi, beklenen davranışlara karar vermektir. Beklenen davranışlar, okulun ya da programın "kuralları”dır. Çocuklar için 5'den fazla beklenen davranış belirlenmez. Çünkü okul öncesindeki çocukların yaşı küçük olduğu için onların anlayabileceği spesifik ve az beklenen davranış belirlemek davranışın kazanımını kolaylaştırır. Örneğin, okul öncesindeki çocukların kelime hazinesinde var olan ve böylelikle daha kolay hatırlamalarını sağlayacak iki kelime "Dikkatli Olma” ve "Kibar Olma”, beklenen davranışlardan olabilir. Ayrıca, okul takımı, "Sorumluluk Sahibi Olma” beklenen davranışını iki nedenden dolayı seçebilir. Birincisi okul öncesinde öğrenmesi gereken bazı davranışları içermesi; ikincisi ilkokul döneminde buna bağlı olarak yeni davranışlar kazanmasıdır. Okul öncesinde, "Sorumluluk Sahibi Olma" davranışı bulunduğu ortamı temiz tutma anlamında kullanılabilir (Stormont, Lewis ve Beckner, 2005). Ayrıca öykülerle pozitif davranış kazandırma okul öncesi eğitiminde önemsenen bir uygulamadır. Okul öncesindeki öğrencilerin davranışları akıllarında tutup uygulayabilmelerinde öyküler önemlidir (Lacina ve Stetson, 2013).

Aşağıda okul öncesinde beklenen davranışları gösteren örnek bir tablo hazırlanmıştır (Stormont, Lewis ve Beckner, 2005).

Tablo 1: Program Kuralları ve Tanımlanmış Beklenen Davranışların Basit Matrisi (Stormont, Lewis ve Beckner 2005'den uyarlanmıştır.)

\begin{tabular}{|l|l|l|l|l|}
\hline & Sınıf & Dışarı & Otobüs & Koridor \\
\hline Dikkatli Olma & Ayaklarının üzerinde yürü & Öğretmeni dinle & Yerinde otur & Ayaklarının \\
& Yerine otur & Kendi yönünde sessizce & Sürücüyü dinle & üzerinde yürü \\
& Öğretmeni dinle & git & Kaldırımda bekle & Önüne bak \\
& & Motorlu araçlara karşı & & Ellerini yanında tut \\
& & dikkatli ol & & \\
\hline
\end{tabular}




\begin{tabular}{|l|l|l|l|l|}
\hline Kibar Olma & Oyuncaklarını paylaş & Sirayla yap & Sürücüye & Alçak ses tonu \\
& Ellerini sakin tut & Kibar kelimeler kullan & "merhaba" de & kullan \\
& Arkadaşlarına kibar & & Kibar kelimeler & Başkalarına \\
& kelimeler kullan. & & kullan & gülümse \\
\hline Sorumluluk Sahibi & Temiz tut & & Emniyet kemerini & Sıranda bekle \\
Olma & Ellerini yıka & Oyuncaklarını yerine & bağla & Ellerini \\
& & koy & Sirt çantanı al & yanında tut \\
\hline
\end{tabular}

Öğretmenlerin, öğrencinin olumlu davranış geliştirmesinde büyük bir etkileri vardır. Öğretmen ve öğrenci arasındaki ilişki önemlidir. Öğretmen ve öğrenci arasında olumlu bir ilişki geliştiğinde öğrencinin başarılı olması ve olumlu davranışlar göstermesi daha olağandır. Öğrenci öğretmeniyle olumlu bir ilişki geliştirdiğinde akademik ve davranışsal olarak daha iyiye gider. Öğretmen, öğrencinin olumsuz davranışını pozitif davranışa dönüştürmesi için öğrenciye seçenek sunmalıdır. Böylelikle sınıf içinde yaşanabilecek psikolojik şiddettin de önüne geçebilir. Örneğin, okul öncesindeki bir öğrenci arkadaşlarıyla oynamak istediğinde ve arkadaşları onunla oynamak istemediğini belirttiğinde kendisiyle oyun oynanmayan öğrenci, kendisini reddedilmiş, sinirli ve yalnız hisseder. Psikolojik şiddet, olumsuz sınıf ortamı oluşturarak öğrenmeyi engeller (Lacina ve Stetson, 2013). Öğrencilerin, sosyal-duygusal gelişimleri ve akademik başarıları arasındaki ilişkiyi inceleyen okul öncesine ait bir pilot uygulamada, sosyal-duygusal öğrenmenin ve akademik öğrenmenin kullanıldığı bir grup riskli davranış sergileyen öğrencilerin ‘öz düzenleme’ becerilerinin geliştiği görülmüştür (Daunic, Corbett, Smith, Barnes, Santiago-Poventud, Chalfant, Pitts ve Gleaton,2013).

İlkokul ve okulda pozitif davranış desteği. PDD, öncelikle pozitif davranışın tanımlanması gerektiğini belirtir. Pozitif davranışın örneklendirilmesi ve öğrenciye anlatılması gerekir (Stormont, Lewis ve Beckner, 2005; Ziomek-Daigle ve Cavin, 2015; Child Care Bureau). Örneğin, pozitif bir davranış olan sorumluluk sahibi olma davranışı örneklerle 
açıklanmalıdır. İlkokul 4. sınıf öğrencisine sorumluk sahibi olma davranışı kazandırılmak isteniyorsa; "ödev yapma, dersi dinleme, vs." şeklinde sorumluk sahibi olma davranış1 örneklendirilerek somutlaştırılmalıdır. Fakat PDD uygulaması için, öncelikli olarak okulda ve sınıfta akademik başarıyı ve sosyal öğrenmeyi engelleyen saç çekme, sataşma, diğer çocuklara vurma, 1sırma, oyuncak ve materyallere zarar verme, bağırma (Child Care Bureau), ödev yapmama şeklinde problemli davranışları tanımlamak gerekir. İlkokul çağında uygulanan pozitif davranış desteği çalışmalarına velilerin de dâhil edilmesi, velilerden öğrenciye yönelik verileri toplamasının istenmesi, PDD’nin etkililiğini artırmaktadır (Ziomek-Daigle ve Cavin, 2015).

Lisede pozitif davranış desteği. PDD uygulamaları, daha çok ilk ve ortaokul seviyesinde uygulanmaktadır. Lise düzeyinde, yeterli uygulamalar ise mevcut değildir ve ergenlerde problemli davranışların ve sorumluluk sahibi olma davranışlarının nasıl tanımlanıp ele alınacağını ortaya koyan çalışmalara ihtiyaç duyulmaktadır (Flannery ve BohanonEdmonson, 2005, s. 117; Sugai ve Flannery, 2005, s.3).

PDD'de, öğrencilerin sosyalleşmesi PDD’nin ana amaçlarındandır. Özellikle lisede uygulanan PDD programları, ergenlerin sosyalleşmesini, ilkokul ve ortaokul programlarına göre daha fazla önemser ve sosyalleşme lisede PDD programlarının hem amacı hem de etkinliği olarak kendini gösterir. Okuldaki disiplin ve şiddet problemlerinin çözümünde, insanlararası ilişkiden bir diğer deyişle sosyallikten destek alınır. Okul çalışanları, veliler, öğrenciler ve diğer gönüllüler bir araya gelerek okulun düzenlediği programlar çerçevesinde verilen eğitimler ve görev paylaşımlarıyla disiplin sorunlarını çözüme kavuştururlar. Öğrencinin sosyal becerilerinin geliştirilmesi ve davranış yönetiminin bu şekilde sağlanması pozitif okul iklimin oluşmasında önemlidir (Knoff, 2000). Bu yüzden bireyin, kişiliğini oluşturduğu ve sosyal yaşamla iç içe olduğu ergenlik döneminde sosyalleşme önceki gelişim dönemlerine göre daha 
fazla önem kazanır. PDD, kişinin yaşam stilini çevresindeki öğretmen, anne baba ve arkadaşlar gibi kişilerle ilişkilerini değiştirmesine yardım eder (Carr, Dunlap, Horner, Koegel, Turnbull, Anderson, Sailor, Anderson, Albin, Koegel ve Fox2002).

Lise öğrencilerinin, okulda ve hayatlarında değişiklik yapmaları için onları motive edici yollar bulunmalıdır (Flannery ve Bohanon-Edmonson, 2005, s. 118). Çünkü bilindiği üzere, lise bireyin kimlik ve kişilik kazanma evresidir ve bu evrenin sağlıklı bir şekilde geçirilmesi, bireyin kişilik gelişimini destekleyecektir. Bu nedenle lise öğrencilerine yönelik hazırlanacak pozitif davranış desteği programının iletişim, duygu farkındalığı, öfke kontrolü gibi sosyal becerileri geliştirici unsurlara dayanması önemlidir. Lise döneminde, ergenlerin sosyal ve gelişimsel yönlerinin üzerinde durulmaktadır. Bu dönemde öğrencinin, kendi ilgilerini, güçlü yanlarını, hayallerini/hedeflerini nasıl tanımladığı önemlidir (Scott ve Eber, 2005, s. 89)Bu yaş grubunda bulunan ve okula devam eden ergen bireylere PDD'nin katkısı kaçınılmaz olacağından eğitim programlarıyla harmanlaşmış bu eğitim metodunun lisede verilmesi çok önem arz etmektedir.

\section{Sonuç, Tartışma ve Öneriler}

Amerika'da gittikçe yaygınlık kazanan PDD, eğitim sürecine olumlu olarak etki etmiştir(Garcia, 2014; Children’s Defense Fund). Pozitif davranış desteği, her ne kadar ilk zamanlar engeli olan öğrenciler için düzenlense de ilerleyen süreçlerde bütün öğrencileri hedef popülâsyonadâhil etmiştir. Okul çapında pozitif davranış destekleri, (a) öğrencilerin okulda geçirdiği süreyi, (b) öğrencilerin meşgul oldukları dakika sayısını ve (c) öğretim sırasında öğrencilerin akademik katılım düzeyini artırarak öğrenme ortamlarını iyileştirmek için tasarlanmıştır (Gage, Sugai, Lewis ve Brzozowy,2015) ve sadece problemli davranışlar sergileyen öğrencileri koruyucu rol üstlenmeyen aynı zamanda okuldaki diğer öğrenciler için 
de önleyici bir rolü olan PDD, eğitim programlarının eğitim durumları boyutuna önemli katkılar sağlamaktadır.

Okulda yaşanan disiplin suçları, okulun ve sınıfın iklimini bozmakta ve okulları güvenli ortamlar olmaktan uzaklaştırmaktadır. Okul ortamının yeteri düzeyde güvenli olmaması, eğitim için ayrılan kaynakların boşa harcanmasına neden olmaktadır. Bunun yanı sıra öğrencinin okulu bırakması, potansiyelinin altında başarı göstermesi, suça dâhil olması ya da bazı suçlardan dolayı mağduriyetler yaşaması gibi bireysel kayıplar da yaşanabilmektedir. Çünkü bireyin sosyal-duygusal yapısı ve akademik başarısı arasında önemli bir ilişki vardır. Okulda kendini güvende hissetmeyen bir öğrenci potansiyelinin altında başarı gösterecektir(Lacina ve Stetson, 2013; Waller, vd., 2015). Ayrıca disiplinin istenilen düzeyde sağlanamadığı okullarda öğretmen ve yöneticiler sürekli olarak enerjilerini ve vakitlerini öğrencilerin olumsuz davranışlarına harcamaktadır (Memduhoğlu, Mazlum ve Alav, 2015).Bu ve benzeri sorunlar eğitim programlarının eğitim durumları boyutunda yaşanan aksaklık ve eksikliktir. Bu nedenle eğitim durumlarına katkı sağlayacağı düşünülen pozitif davranış desteği eğitim süreçlerine değerli katkılar sağlayacaktır.

Okulun eğitim durumlarının düzeltilmemesi kurum olarak okulu örgüt depresyonuna ve dolayısıyla okul çalışanlarını da tükenmişlik, iş doyumsuzluğu, motivasyon kaybı ve benzeri durumlara sürükleyebilecektir. Bunun önlenmesi için okul ortamlarının sürekli olarak revize edilmesi, uzman gözetiminde eğitimlere tabi tutulması gerekmektedir. Tam da bu noktada, PDD, bu ve benzeri sorunlara çözüm olabilecek bir öneri konumundadır. Çünkü PDD, okul genelini temel alır ve sürekli olarak okulla ilgili yaptığı çalışmalarla ilgili değerlendirmeler yapar. $\mathrm{Bu}$ değerlendirmeleri bazen nitel bazen nicel bazen de hem nicel hem de nitel veri toplama araçlarının kullanıldığı karma araştırma yöntemleriyle yapar. Okulla ilgili yapılan çalışmalar, okulda yaşanmış disiplin sorunları, bireylerle ilgili sosyal ve akademik bilgiler ve veri toplama araçları ve verilerin sonuçları web tabanlı sistemlere aktarılır (Bohanon ve $\mathrm{Wu}$, 
2014; Simonsen, Sugai ve Negron, 2008; Şahin ve Ekici, 2009). Böylelikle okula gelen her çalışan okulla ve öğrencilerle ilgili bilgilere bir sistem üzerinden ulaşabildiği için o ana kadar okul için yapılan tüm çalışmaları sil baştan yapmak yerine eğitimdeki süreklilik sağlanmış olur. Ayrıca PDD, olabildiğince veliyi işbirliğine davet eder. Veliyi, öğrencinin durumuyla ilgili bilgilendirmenin yanı sıra velinin eksik olduğu konularda veliye eğitimler verir ve velinin de öğrenciyle ilgili veri toplamasını sağlar. Böylelikle öğrencinin okul dışındaki durumuyla ilgili bilgiler elde edilerek çok yönlü destek sağlanır (Gottfredson, Gottfredson ve Hybl, 1993; Horner, vd., 2004).

\section{Makalenin Bilimdeki Konumu (Yeri)}

Eğitim Bilimleri Bölümü

\section{Makalenin Bilimdeki Özgünlüğü}

Okullarda, eğitim programları aracılığıyla ülkenin ve toplumun hedeflerini hayata dönüştürebilen önemli kurumlardır. Fakat bazen eğitim programları okullarda istenilen başarıya ulaşamamaktadır. Bu durum genelde okullarda var olan şiddet gibi olumsuz davranışlardan kaynaklanmaktadır. Okullar şiddet ve benzeri davranışları bir disiplin sorunu olarak ele almakta ve çözüm olarak da genellikle disiplin cezaları seçilmektedir. Buna rağmen var olan sorunlar çoğu zaman devam etmektedir. Okullardaki şiddeti önlemeye ve azaltmaya yönelik bir çözüm olarak PDD uygulanabilir. Ayrıca okullardaki şiddetin yanı sıra hem eğitim ortamında hem de sanal dünyada var olan zorbalık öğrencilerin ders motivasyonlarına olumsuz olarak etki etmektedir. Bunun yanı sıra zorbalığın getirdiği duygusal hasar, öğrencinin sosyal becerilerini ve problem çözebilme yetisini de olumsuz olarak etkileyebilmektedir. Bu ve benzeri sorunların çözümü için pozitif davranış desteği alternatif bir uygulama olabilir. Fakat Türkiye'de konuyla ilgili yeterli çalışma bulunmadığından bu çalışma, bu sorunlara çözüm geliştirmek için alana katk1 sağlayabilir. 


\section{Kaynaklar}

Balc1, A. (2013). Sosyal bilimlerde araştırma: Yöntem, teknik ve ilkeler (10.bask1). Ankara: Pegem A. Yayıncılik.

Bohanon, H. \& Wu, M. J. (2014). Developing buy-in for positive behavior support in secondary settings. Preventing School Failure, 58(4), 223-229.

Carr, E.G., Dunlap, G., Horner, R. H., Koegel, R. L., Turnbull, A. P., Anderson, J. L., Sailor, W., Anderson, J. L., Albin, R. W., Koegel, L. K. \& Fox, L. (2002). Positive behavior support: Evolution of an applied science. Journal of Positive Behavior Interventions, 4(1), 4-20.

Child Care Bureau(t.y.).Center on the Social and EmotionalFoundations for Early Learning.Positive Behavior Support: An Individualized Approach for Addressing Challenging BehaviorWeb.Erişim tarihi: 11.08.2017.

http://csefel.vanderbilt.edu/briefs/wwb10.pdf.

Children's Defense Fund (t.y.). Positive Behavioral Supports Overview.

Erişim tarihi: 20.06 .2017

Erişimadresi:https://www.aasa.org/uploadedFiles/Childrens_Programs/PBIS\%20factshe et.pdf

Crimmins, D. Farrell, A. F., Smith, P. W. \& Bailey, A. (2007). Positive strategies for students with behavior problems. Paul H. Brookes Publishing Co.: Baltimore.

Daunic, A., Corbett, N., Smith, S., Barnes, T., Santiago-Poventud, L., Chalfant, P., Pitts, D. \& Gleaton, J. (2013). Brief report: Integrating social-emotional learning with literacy instruction: An intervention for children at risk for emotional and behavioral disorders. Behavioral Disorders, 39, 1, 43-51. 
Dunlap, G., Kincaid, D., Horner, R. H., Knoster, T. \& Bradshaw, C. P. (2014). A comment on the term "positive behavior support".Journal of Positive Bejavior Interventions, 16(3), 133-136.

Feuerborn, L. L., Tyre, A. D. \& King, J. P. (2015). The staff perceptions of behavior and discipline survey: A tool to help achieve systemic change through schoolwide positive behavior support. Journal of Positive Behavior Intervention, 17(2), 116-126.

Flannery, K. B. \& Sugai, G. (2005). Positive Behavior Support in High Schools: Monograph from the 2004 Illinois High School Forum of Positive Behavioral Interventions and Supports. Hank Bohanon-Edmonsoni K. Brigid Flannery, Lucille Eber and George Sugai (Eds.). High school positive behavior support survey: What the high schools doing. (s.95-111). Naperville, Illinois.

Gage, N. A., Sugai, G., Lewis, T. J. \& Brzozowy, S. (2015). Academic achievement and school-wide positive behavior supports. Journal of Disability Policy Studies, 25(4), 199209.

Garcia, L. E. (2014). Positive behavioral interventions and supports: A multi-tiered framework that works for every student. An Nea Policy Brief, National Education Association, 1-6.

Glover, D. M. (2005). Positive Behavior Support in High Schools: Monograph from the 2004 Illinois High School Forum of Pozitive Behavioral Interventions and Supports. Hank Bohanon-Edmonsoni K. Brigid Flannery, Lucille Eber ve George Sugai (Ed.). Instruction of behavior in high schools implementing positive behavior support (s.5561). Naperville, Illinois.

Gottfredson, D. C., Gottfredson, G. D. \& Hybl, L. G. (1993). Managing adolescent behavior a multiyear, multischool study. American Educational Research Journal, 30, 179-215.

Horner, R. H., Todd, A. W., Lewis-Palmer, T., Irvin, L. K., Sugai, G. ve Boland, J. B. (2004). 
The school-wide evaluation tool (SET) a research instrument for assessing schoolwide positive behavior support. Journal of Positive Behavior Inventions, 6(1), 3-12.

Horner, R. H., Sugai, G., Smolkowski, K., Eber, L., Nakasato, J., Todd, A. W. ve Esperanza, J. (2009). A randomized, wait-list controlled effectiveness trial assessing school-wide positive behavior support in elementary schools. Journal of Positive Behavior Interventions, 11(3), 133-144.

Horner, R. H., Sugai, G. \& Anderson, C. M. (2010). Examining the evidence base for schoolwide positive behavior support. Focus on Exceptional Children, 42(8), 1-14.

Johnston, J. M., Foxx, R. M., Jacobson, J. W., Green, G. \& Mulick, J. A. (2006). Positive behavior support and applied behavior analysis. The Behavior Analyst, 29(1), 51-74.

Karasar, N. (2011). Bilimsel araştırma yöntemi (22.baskı). Ankara: Nobel Yayıncılık.

Kincaid, D., Dunlap, G., Kern, L., Lane, K. L., Bambara, L. M., Brown, F., Fox, L. \& Knoster, T. P. (2016). Positive behavior support a proposal for updating and refining the definition. Journal of Positive Behavior Interventions, 18(2), 69-73.

Knoff, H. M. (2000). Organizational development and strategic planning for the millennium; A blueprint toward effective school discipline, safety, and crisis prevention. Psychology in the Schools, 31(1), 17-32.

Köklü, E. (2006). Representation of Aggression in Child and Adolescent Protagonists in the Short Stories of Saki (Hector Hugh Munro). (Yayımlanmamış yüksek lisans tezi). Hacettepe Üniversitesi/Sosyal Bilimler Enstitüsü, Ankara.

Lacina, J. \& Stetson, R. (2013). Using children's literature to support positive behavior. Young Children, 34-41.

Mcintosh, K., Mercer, S. H., Hume, A. E., Frank, J. L., Turri, M. G. ve Mathews, S. (2013). Factors related to sustained implementation of schoolwide positive behavior support. Exceptional Children, 79(3), 293-311. 
Memduhoğlu, H. B., Mazlum, M. M. ve Alav, Ö. (2015). Türkiye'de alternatif eğitim uygulamalarına ilişkin öğretmenlerin ve öğretim üyelerinin görüşleri. Eğitim ve Bilim, 40(179), 69-87.

Pişkin, M., Öğülmüş, S. ve Boysan, M. (2011). Güvenli Ortamı Oluşturma Öğretmen ve Yönetici Kitabl. TÜBİTAK.

Rogers, C. R. (1994). Etkileşim Grupları (Çev. Hamdullah Erbil). Ekin Yayınları: Ankara. Safran, S. P. \& Oswald, K. (2003). Positive behavior supports: Can schools reshape disciplinary practices. Exceptional Children, 69(3), 361-373.

Scott, N., Eber, L., Malloy, J. ve Cormier, G. (2005). Positive Behavior Support in High Schools: Monograph from the 2004 Illinois High School Forum of Pozitive Behavioral Interventions and Supports. Hank Bohanon-Edmonsoni K. Brigid Flannery, Lucille Eber ve George Sugai (Eds.). Intensive comprehensive level of support for high school students. (83-94). Naperville, Illinois.

Simonsen, B., Sugai, G. \& Negron, M. (2008). Schoolwide positive behavior supports primary systems and practices. Positive Behavior Interventions and Supports, 40(6), 3240.

Simonsen, B., Britton, L. ve Young, D. (2010). School-wide positive behavior support in an alternative school setting. Journal of Positive Behavior Interventions, 12(3), 180-191.

Simonsen, B., Jeffrey-Pearsall, J., Sugai, G. \& McCurdy, B. (2011). Alternative setting-wide positive behavior support. Behavioral Disorders, 36(4),213-224.

Sprague, J. \& Horner, R. (2007). Handbook of School Violence and School Safety: From Research to Practice. Shane R. Jimerson and Michael J. Furlong (Eds.). School wide positive behavioral support. Erlbaum Associates, Inc.

Sugai, G. \& Horner, R. (2002). The evolution of discipline practices: School-wide positive behavior supports. Child \& Family Behavior Therapy, 24:1(2), 23-50. 
Sugai, G. \& Flannery, K. B. (2005). Positive Behavior Support in High Schools:

Monograph from the 2004 Illinois High School Forum of Pozitive Behavioral Interventions and Supports. Hank Bohanon-Edmonsoni K. Brigid Flannery, Lucille Eber ve George Sugai (Eds.). School-wide positive behavior support in high schools: What will it take? (s. 1-15). Naperville, Illinois.

Stormont, M., Lewis, T. J. ve Beckner, R. (2005). Positive behavior support systems: Applying key features in preschool settings. Teaching Exceptional Children, 37(6), 4249.

Şahin, İ. ve Kesici, Ş. (2009). Web-assisted positive behavior support. İlköğretimOnline, 8(1), 224-230.

Waller, R., Gardner, F., Dishion, T., Sitnick, S. L., Shaw, D. S., Winter, C. E. \&Wilson, M. (2015). Early parental positive behavior support and childhood adjusment: Addressing enduring questions with new methods. Social Development, 24(2), 304-322.

Wilson, D. B., Gottfredson, D. C. \& Najaka, S. S. (2001). School-based prevention of problem behaviors: A meta-analysis. Journal of Quantitative Criminology, 17(3), 247272.

Ziomek-Daigle, J. ve Cavin, J. (2015). Shaping youth and families through positive behavior support: A call for conselors. The Family Journal: Counseling and Therapy for Couples and Families, 23(4), 368-373.

\section{Summary}

\section{Statement of Problem}

In schools, there are disciplinary problems which affect academic success and school environment. Increasing disciplinary problems, violence, the use of drugs and the like in schools are serious threats to school climate and school security. Increasing disciplinary 
punishments to overcome these problems are not the desired result and disciplinary problems in the school continue to exist. The fact that the problems in the school are not solved despite the increase and increase of the disciplinary punishments indicate that this method is not very effective. Instead of increasing disciplinary punishment to solve these problems, Positive Behavior Support can be an alternative solution. Studies show that Positive Behavior Support is widely used in many schools in America and Europe and schools with positive behavior support reduce disciplinary and other problems. Positive behavioral support plays a preventive and promoting role in schools and positive behavioral support is considered an alternative to traditional school practices. It is possible to find many studies about positive behavior support in literature. However, there are limited studies on positive behavior support in Turkey.

\section{Purpose of the Study}

The aim of this study is to introduce readers to Positive Behavior Support, which is a valuable contribution to the educational process.

\section{Method}

This study is a literature study and descriptive method is used in the study. Studies conducted on Positive Behavior Support for this research have been reviewed and these studies constitute the sources of the research. ERIC, Scopus, SSCI databases were taken as the basis of reaching the information. Also, official internet sites and studies about positive behavior support were used as resources.

\section{Findings}

Instead of increasing disciplinary punishments, Positive Behavioral Support, which develops preventive and developmental plans at school and is an alternative to traditional disciplinary practices, creates a school-wide system for securing school climate (Safran ve Oswald, 2003; Simonsen, Sugai ve Negron, 2008; Horner, vd. 2009; Sugai ve Horner, 2002). 
Positive Behavior Support or Positive Behavior Management is a program and system widely used in many schools in America and Europe (Sugai ve Flannery, 2005, s.3; Johnston, vd., 2006; Carr, vd., 2002). Positive Behavior Support is unique for each school because all schools have diffent problems one another, and in each of school level, students experience various problems. Hence Positive Behavior Support programs are reformed according to the school problems and school levels (Simonsen, vd. 2011; Mcintosh, vd., 2013; Garcia, 2014). Altough Positive Behavior Support is practiced in all places of schools (such as class, hallway, canteen), the groups of students are changeable. For example, while some applications of Positive Behavior Support are for the specific groups such as autistic students or students who do not do homework, others are for all of the students (Horner, Sugai ve Anderson, 2010).

Positive Behavior Support is also a system and it works in cooperation with parents, teachers, deputy school heads and specialist from various fields (Waller, vd., 2015).. Thus, Positive Behavior Support develops behaviors which schools expect. It solves problems in schools such as disciplinary problems, violence, the use of drugs.

In schools using Positive Behavior Support, disciplinary problems decrease (Bohanon ve Wu, 2014). Besides, studies show that in schools which use Positive Behavior Support, using drugs and alcohol, leaving school and truantry and other problems decrease (Wilson, Gottfredson ve Najaka, 2001).

\section{Discussion, Conclusion and Suggestions}

Positive Behavior Support has affected education systems positively (Children's Defense Fund; Garcia, 2014). Firstly, Positive Behavior Support occurs for disabled students, but then, as Positive Behavior Support earns success, it has been used for all school-wide students since 2004 (Children's Defense Fund; Garcia, 2014). Also, at the beginning, Positive Behavior Support was practiced at elementary schools and middle schools. In these academic periods, Positive Behavior Support is a successfull system, and so it is used in preschool and 
high school too (Stormont, Lewis ve Beckner, 2005) but it can be said that Positive Behavior Support is new for high school. Now, Positive Behavior Support focuses on not only students displaying problem behavior but also others. So it has a preventive role for other students. Thus, Positive Behavior Support will help schools. Studies inticated that disciplinary problems begin to decrease in schools using Positive Behavior Support (Bohanon ve Wu, 2014).

There is a positive relationship between social moods and academic success. Positive Behavior Support makes significant contributes academic and social success in schools by reforming school envirenments. Also Positive Behavior Support prevents violence and disciplinary problems. So it can be an alternative for violence in schools.

There is a limited Turkish publication about positive behavior support which is common and common in literature. Positive Behavior Support can be considered to be beneficial in the education system in Turkey. Therefore, all kinds of publications or implementations are essential. 